\title{
Tweens Perception of Advertising Using an Older Cognitive Age
}

\author{
Tetty Rimenda \\ \{rimenta@yahoo.com\} \\ Politeknik Negeri Jakarta, Indonesia
}

\begin{abstract}
Cognitive age is people's perception of the age which is younger or older than their chronological age. This research investigated whether tween had a cognitive age perception. Based on their cognitive, tweens have not been able to understand the concept of a cognitive age, because their cognitive development is still in a concrete operational phase, contrary from social view they are capable. The major purpose of this research was to test tweens and determine if they can be influenced by ads using a cognitive age concept. Data was collected from 115 tween boys and 95 tween girls (1112 years old). This study used experimental design 2 (cognitive age: congruent versus incongruent) x 2 (ad model: male versus female) x 2 (age of model: peer versus older).This study proved that tweens have a perception of the cognitive age. The desire to have products in tween boys and girls is equally aroused by congruence with older advertising models. The desire to evaluate products differs between tween boys and girls. There is no difference between tween boys and tween girls in terms of giving references. The findings also provide information for educators and parents to be more vigilant in looking at various ad.
\end{abstract}

Keywords: cognitive age, congruence, tween

\section{Introduction}

The cognitive age concept is commonly used in an advertising format. Cognitive age is a person's perception of their age, which differs from their chronological age. A 60 year old person may feel that he/she is 50 and their behavior is similar to people that are 50 years old. Cognitive age influences their buying behavior, it can be seen from the choice of products they buy. The concept of cognitive age is applicable for all ages, younger or older. However, characteristic of younger cognitive age is in the contrary to the older cognitive age. Younger people tend to be in older cognitive age, while older people are vise versa.

The objective of this research was to evaluate if tweens can be persuaded by ads with a cognitive age concept. The cognitive age concept is frequently used these days in an ad. Does tween already understand ads message that use the cognitive age concept ? According to psychology, the child' ability to understand advertising message depends on their cognitive development. so the children can not yet understand an ad that uses the concept of cognitive age. Conversely from social view, cognitive is not the only factor for children to understand the ad. The ability of children's to socialize also determines their understanding of advertising.

The novelty of this research because it is done on tween. Tween is a $10-12$ years old child. They are specials because they can influence their parents' buying decision, they are very technological genious, and rapid information development follower. The word tween is originated from the word "in-be-tween". They do not want to be considered children anymore, although they are not completely teenagers .Population of tween is big enough (10\% of Indonesian population) (Indonesia Statistics Bureau = BPS, 2010), so they are an 
attractive market for marketers. In the daily life of society gives different treatment between boys and girls. Physically (biologically) boys are bigger than girls, but psychologically girls are mature faster than boys, this is because of the female hormone estrogen. Hormones also make girls more feminine; visually they are very easily influenced by advertising. Because of differences in the treatment of tween children, one of the purposes of this study was to distinguish testing of tween boy and female girl.

\section{Methodology}

2.1. Hypothesis

"Feeling younger" is a concept which relates to the way somebody thinks. This feeling is related with something positives like healthy, active or success. To arouse this feeling, the researcher use younger ad model .On the other hand, "feeling older" is a concept commonly used for young people who are more responsible and mature. Older ad model was used to arouse the older feeling. When participants saw the ads, perception of participants' cognitive age will interact with perception of ad model. The interaction was derived by congruency. By seeing the models, modeling and imitating process happened, so that participants feel the same or congruent with the model.That's way tween can understand cognitive age concept. Hence, hypothesis 1 is built.

H1. The congruent perception between the tween's cognitive age and the ad model's age has stronger "perception of cognitive age" than incongruent perception of tween cognitive age with the ad model age Sex differences on children can be seen that boys are masculine, and girls are feminine. Social Learning Theory stated that children learn a behavior based on their gender by observing and imitating. It is also easier for children to imitate the behavior of people who have a similar gender to themselves, rather than people who have a different gender [23]. Cognitively, there is no difference between boys and girls (Cognitive Development). Socially, boys can be different from girls. The difference between boys and girls is more influenced by the environment, the way their parents educate them, their family economic status, and technology. Tween girls addicted to shop, brand concious, trend follower, and are easily influenced by ads. For this reason, girls are more likely to grow older than boys. Hence, the next hypothesis is;

H2. The congruent perception between the tween's girls cognitive age and the ad model's age will encourage feeling "perception of the advertised product is for me" is stronger on tween girls who saw older ad model than those who saw similar ad model.

When seeing an ad, consumers will evaluate the advertised product to know whether or not the product suits their need. Functional appropriateness is a factor which used to be a basis in evaluating the suitability of product and consumers' need . In assessing the advertised product, there is a difference between boys and girls. Girls tend to explore more detailed in evaluating information about products, so they are more appropriately grouped into a detailed-based strategy While boys can be grouped into schema-based strategies in product evaluations. Hence, it is assumed that boys tend to use a schema-based strategy and rate the advertised product in the outline. If he feels fit (congruent) with the ad model that offers the product, then he will be encouraged to conduct a further evaluation of the product offered.

The next hypothesis is H3. The congruent perception between the tween's boys cognitive age and the ad model's age will enhance feeling "perception product evaluation" which was advertised by older age ad model was stronger than the one advertised by similar age ad model. Parents' dependence to seek opinions to their children before deciding to buy products makes boys and girls accustomed to referring products. They feels responsible for providing reliable information. This condition indirectly makes the child feel older than his age. Characteristic of tween girl is she likes to talk and convey his opinion, so that he become a source of reference for his friends. The confidence of his friends who made the information from him into a trend setter raises the notion that his way of thinking is also more mature. Allegedly when looking at older ad models, boys and girls will perceive their age as congruent with the ad model, which in turn will affect the perception of referencing it. Information from tween boy is more reliable because they are more detailed in providing information.

So the hypothesis proposed is: H4. The congruent perception between the tween's boys cognitive age and the ad model's age will generate, "perception to refer the product" of those who saw the products advertised by older ad models was stronger that those shown by similar ad models.

This study used experiment design 2 (congruence of participants' cognitive age perception with model's cognitive age perception: congruent versus incongruent) x 2 (advertisement model: boys versus girls) $x 2$ (model's age: similar versus older). Participants were grouped randomly into 4 groups. They will see different 
advertisement models (male with similar age, older male, female with similar age, older female). Manipulation was conducted by showing different advertisements to each manipulation group.

\subsection{Pilot Study}

There are three pilot studies conducted. The first pilot study was to determine the advertising model. Ad model images uploaded from the internet, with criteria: boy, ages ranging from 8-12 and 12 - 16 years old, not famous stars, originating from Asian countries. It is very interesting that white and slightly Indo faces are still considered as people from Asia, because they familiar with indo face. The same process is done to select the ad model of tween girl aged 8-12 years and 12-16 years.

The second pilot study is determine the product to be used, by asking the participants to mention the product that is most familiar with them. The product must be owned, liked and used most often, without mentioning the brand. The result there are 4 types of products selected by participants namely Mobile, Smartphone, Laptop and Ipad. The next step is asking 20 participants to choose the product they like best. Smartphone was selected by 11 participants as the most favorite product, therefore smartphones are used as manipulations in experimentation.

The third pilot study is to determine the text that will be used on the ad. Ad text is taken from the internet, with some modifications. The use of English in this ad because the ability of children to communicate with English is very good. 20 participants, were asked to choose two choices of ad text and they choose : Style. Slim. Metal Celebrate the arrival of the Smartphone, with yours favorite friend as a favorite ads

\subsection{Participant}

Participants selected in this study are tween children, aged 8-12 years old. ] or in grade $4^{\text {th }}$ and $5^{\text {th }} 4-6$ in elementary school. Overall, data was collected for 115 boy participants $(52.25 \%)$ and 95 girl participants $(47.75 \%)$. They came from the middle-upper economic group, which is reflected in how much tuition they pay. Inform consent is sent to the parent through a liaison book and received back within a week

\subsection{Procedures}

Participants asked to choose a lottery for their grouping. Thus, there will be 4 groups: (1) boys who see an ad model whose age is similar to their age (58 people), (2) boys who see an ad model whose age is older than their age (58 people), (3) girls who see an ad model whose age is similar to their age (53 people), (4) girls who see an ad model whose age is older than their age (53 people).The experimenter then explained that this is a program to choose the best advertisement

\section{Result and Discussion}

\subsection{Cognitive Age Perception (CAP)}

From descriptive data obtained information that chronological age of participants between $8-12$ years $(\mathrm{min}=$ 9. $\operatorname{Max}=12, \mathrm{Sd}=0.74)$. While the cognitive age of participants between $9-18$ years $(\min =10 . \mathrm{Max}=18, \mathrm{Sd}$ $=2.10$ ). It can be concluded that the participants' cognitive age is higher than their chronological age. This means that children are already understand the concept of cognitive age.

When participants' cognitive age is compared with the model's cognitive age, there is no significant difference. This may happen because the model's cognitive $(\mathrm{Min}=8 . \mathrm{Max}=18, \mathrm{DS}=2.11)$ age was not too different from the participants' cognitive age.

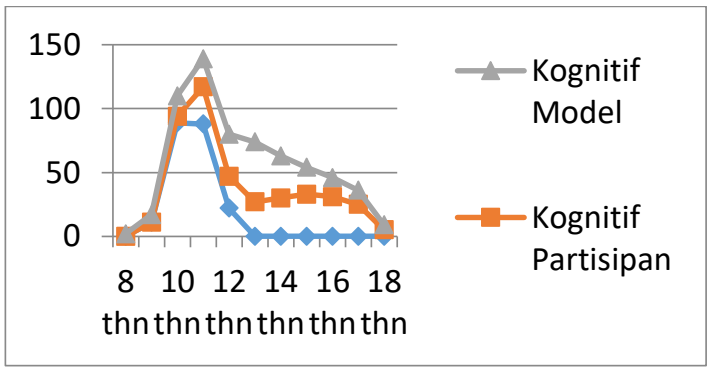

Figure 1. Chronological Age Participants Cognitive Age Participants and Cognitive Age Models 
Further testing is to prove that congruence and incongruence give different effects on the perception of cognitive age. Tests were performed on 210 participants using a median split as a reference to determine congruent and incongruent. From the difference between the cognitive age of the participant and the cognitive age of the model was found median $=2$. The cognitive age perception is said to be congruent when the cognitive age participants and the cognitive age of the model difference smaller or equal to two. Conversely if the difference larger then 2, will be grouped to incongruent group. From this calculation was found, 106 participants were congruent (50.47\%) and 104 incongruent $(49.52 \%)$.

Although the number of participants is congruent is not much different from the number of participants who are incongruent. But the results of the t-test to determine the effect of congruence and incongruence to perceptions of cognitive age show considerable differences, in which the effect given to the cognitive age perception by congruent participants $(\mathrm{M}$ congruent $=3.8836)$ is quite different from the effect of the participants incongruent. ( $\mathrm{M}$ incongruent $=3,1125), \mathrm{F}=0,006, \mathrm{t}=6,592$, sig 0,000 . These differences show that congruent tween-age children have a greater influence on the perception of cognitive age compared with incontinent tween-aged children. This result supports (H1). These findings prove that the understanding the abstract cognitive age is understandable by tween-aged children. Thus, it is evident that the child's ability to judge advertising is not only due to his or her cognitive development but also many other factors, including their ability to socialize (i.e.Consumer Socialization Theor.

\subsection{Product Perception for Me (PPS)}

In this test will be proved the effect of congruence, age of model and sex on the perception of the product for me. To measure the perception 3 questions are used. These three questions are tested by factor analysis. The result is Bartlett's test 0.511>0.5, with sig 0.000. These three questions can form one factor with anti image correlation $(0,508 ; 0.575 ; 0,507)$. So this instrument can be used in the measurement because it is considered valid and reliable.

The t test was performed to test the difference in variance of congruence, model age and sex. The test result with Independent Sample $\mathrm{T}$ test shows that for the perception of the product for me (PPS), there is a difference between congruence variable, gender and model age. Further testing is done by using GLM Univariate. Levene's test results showed the value of $F(1,219)$ sig 0.294 reinforces the $t$ test that has been done, which concludes that there are differences in the variance of independent variables.

This test also proves that female participants are congruent when looking at older ad models $(\mathrm{M}=$ 3.9647).This result is greater than that of the male participants seeing older advertising models $(\mathrm{M}=$ ris greater than the male tween participants who saw the peer ad model $(\mathrm{M}=2.8963)$. This finding supports Hypothesis 2. From these findings, it can be concluded that although tween girls and tween boys are equally congruent when looking at older ad models, congruent tweens girls $(\mathrm{M}=3.9647)$ are larger than congruent boys $(\mathrm{M}=3.4318)$. Subsequent findings of both boys and girls are equally influential for the perception of the product for me (PPS), but the influence of the tween girls is greater than the influence of the tween boys. These findings also show that the cognitive age perception of tween girls is very strong

\subsection{Product Evaluation Perception (PEP)}

Hypothesis 3 to examine the differences between the tween boys and the tween girls in a product evaluation. Tween boys, perform evaluation based on schema-based strategy. The evaluation process is done by calling back the information that has been owned, so that the evaluation process can be done in outline. Allegedly when a tween boy perceives his age is congruent with the perception of the cognitive age of the ad model, then he will make the process of elaboration of information he already has.

The Levene's test $(F=1,631)$ sig 0.128 indicates that there is a variance in the variable. The test results show that in congruent conditions, the tween boys give greater influence to the perception of larger product evaluation (older $\mathrm{M}=3,5294>\mathrm{M}$ pe $=3$, 0513. This means that if the boy is persuaded with the older ad model, will lead to congruence and ultimately it will elaborate on the information it possesses, to evaluate the products offered. Thus it can be concluded that tween boys will only do product evaluation if he feel congruent with older advertising models that offer products. The findings can be used by marketers who will market their products to parents, can be through the mediation of their children, because the function of the child as a great influence on the purchasing decision of their parents. 


\subsection{Product Reference Perception (PMR)}

The $t$ test was performed to test the difference in variance of congruence, the age of the model showed that for the perception for reference (PMR) there was a difference between the congruence variable, and the model age but no variance difference in sex, Further test results the influence of the tween boys who saw the older ad model $\mathrm{M}=3.4615$ were almost identical to the influence of the tween girls who saw the older ad model $\mathrm{M}=$ 3.9474. Hence, there is no difference between the tween male and female children in providing references. When the partial testing is done, gender factors are not found to have a significant effect on the perception for reference $(F=0.314$, sig, 576). The three variables interacted, but did not have a significant effect on the perception to reference ( $\mathrm{F}(1,737) \mathrm{sig}, 189)$. In other words, there is no difference between the tween boys and tween girls in influencing the perception for reference (rejecting hypothesis 4 ).

\section{Conclusion}

The results of the study indicate that the tween child has understood the advertisement which contains the concept of cognitive age, so that if this concept is used in advertising it can influence the purchase of products by tween. For this reason, it is recommended that parents always accompany their children while watching TV that contains advertisements that use the concept of cognitive age in their advertisements. the concept of cognitive age can be used by the government in conveying social messages, for example the habit of brushing teeth before going to sleep is very good for children. If the advert is played by an older advertising star, it can make the child follow this good behavior

\section{Limitation of research}

The limitation of this study is that the participants are still tween. They are bound to school time, parental permission, and not all schools give freedom to take data at the time of study, so that the arrangement of the experiment is very dependent on the learning conditions at school. for further research it is recommended to take data at the time of the holidays, or when the child is carrying out my extra activities

\section{References}

Andersen, LP, Tufted B, Rasmussen J \& Chan K. Tween and New Media In Denmark and Hong Kong, Journal of Consumer Marketing, 24/6, pp 340-350 (2007).

Bandura, Albert. Social Cognitive Theory : An Agentic Persceptive, Asian Journal of Social Psychology 2, pp 21-41 (1999).

Barak, Benny. Age Identity : A Cross-cultural approach, International Journal of Behavioral Development, 33(1), 2-11 (2009).

Blichfeldt BS, Pedersen B, Johansen A, Hansen L (2010) : Tween tourist : children and decision making

Chang, Chingching. Chronological Age versus cognitive age for younger consumers. Journal of Advertising 37,3 (2008).

Chang, Chingching. Masculinity and Cognitive Age Perception : An Examination of their Relationship and Implications for Advertising Persuasion, Sex Roles, 61, 434 - 447 (2009).

Cleaver, Megan \& Muller Thommas E. I want to pretend I'm eleven years younger : subjective age and senior's motives for vacation travel, Social Indicator Research, 60 (2001).

Cook DT, Kaiser SB. Betwixt and be tween : Age Ambiguity and the sexualization of female consuming subject Journal of Consumer Culture (2004).

Drake-Bridges, B Burgess. Personal preferences of tween shopper, Journal of Fashion Marketing (2010).

Eisend. A meta-analysis of gender roles in advertising Journal of the Academy of Marketing Science (2010).

Flurry, LA dan Burns, Alvin C. Children's Influence in Purchase Decisions : A Social Power Theory Approach, Journal of Business (2005).

Galambos,Nancy L, Turner, Pamela K \& Weaver Lauree C Tilton. Chronological and Subjective Age in Emerging Adulthood: The Crossover Effect, Journal of Adolescent Research, 20 No 5, 538-56 (2005).

Guiot, Denis. Subjective Age Biases among Adolescent Girls, Advance in Consumer Research vol 27, 215-223 (2000).

Gwinner, Kevin P \& Stephens, Nancy. Testing the Implied Mediational Role of Cognitive Age, Psychologi \& Marketing, vol 18(10) pp 1031-1048 (2001). 
John, DR. Consumer Socialization of Children: A Retrospective look at Twenty-five years of research. Journal of Consumer Research 26, 183-213 (1999).

Kaur, Pavleen, Singh, Raghbir. Children in Family Purchase Decision Making in India and The West : A Review, Academy of Marketing Science Review 8, 1-28 (2006).

Keller, Margit dan Veronika Kalmus. What makes me cool? Estonian Tween's interpretative repertoires, Young Consumers Vol. 10 No.4 pp 329-341(2009).

Kurnit, Paul. KGOY Reconsidered : kids just want to be kids, Advertising \& Marketing to Children, January$\operatorname{March}(2004)$.

Rubin, David C \& Berntsen, Dorthe: People over forty feel $20 \%$ younger than their age : Subjective age across the lifespan, Psychomatic Bulletin Review, 13(5) 776-80 (2006).

Siegel, David L, Coffey, Timothy J \& Livingston Gregory: The Great Tween Buying Machine, Capturing Your Share of the Multibillion Dollar Tween Market,Chicago, Dearborn Trade Publishing (2004).

Stephens, Nancy Cognitive Age : A Useful Concept for Advertising ?, Journal of Advertising Vol. XX Number $4(1991)$

Szmigin, Isabelle \& Carrigan, Marylyn: The Older Consumer as Innovator, Does Cognitive Age hold the key?, Journal of Marketing Management, 16, 505-527 (2000)

Tinson, Julie \& Clive Nancarrow: GROw'ing up:Tweenagers involvement in family decision making, Journal of Consumer Marketing 24/3 160-170 (2007) 